\section{P3-S1.41 COINFECTION OF NEISSERIA GONORRHOEAE AND CHLAMYDIA TRACHOMATIS IN SYMPTOMATIC AND ASYMPTOMATIC WOMEN IN INDIA: IMPLICATIONS IN REPRODUCTIVE HEALTH}

doi:10.1136/sextrans-2011-050108.441

D Sachdev, S Sonkar, P Mishra, A Patel, D Saluja. Univesity of Delhi, Delhi, India

Background Despite the recent advances in diagnosis, Neisseraia gonorrhoeae (NG) and Chlamydia trachomatis (CT) remain leading cause of STDs worldwide and account for STI's morbidity leading to acquisition of HIV and HPV infection. Coinfection of gonococcus and Chlamydia is reported from various countries. In recent study we reported high rate of infection by CT using an in house developed PCR method. A number of studies also suggest increasing rate of antibiotic resistance in NG. Thus we developed a rapid, specific and cost effective diagnostic method to detect prevalence of co infection by NG and CT. Methodology: (1) Unique gene sequence of CT and NG were amplified from gDNA isolated from endocervical swabs. (2) Validation of in house PCR method using Roche AMPLICOR Micro well plate CT/NG kit. (3) Use of molecular beacon to develop easy visual method. (4) Establishment of multiplex PCR (mPCR) for simultaneous detection of CT and NG.

Results 360 clinical samples were used to validate in house PCR assay. Discrepancy of the samples was resolved by amplifying genes encoding for outer membrane proteins ( $r m p$ for NG and ompA for CT). The resolved PPV and NPV were found to be $94 \%$ and $99 \%$ for CT, $92.0 \%$ and $96 \%$ for NG. Molecular beacon probe was used which helped in visualisation of PCR product directly in tube using dark reader which also improved the sensitivity of assay. The overall infection rate by NG was $26 \%$ and $8.6 \%$ in symptomatic and asymptomatic patients while that of CT was $26.3 \%$ and $21 \%$ respectively. To make the method easy to use in remote areas with minimum laboratory infrastructure, the in house PCR assay was standardised for detection using dry swabs, with crude DNA preparation and stabilisation of reagents at 4C (up to 6 months) was achieved for easy transportation and storage. Using single PCRs, coinfection by CT and NG was found to be $18 \%$ in symptomatic $(74 / 410)$ and $5 \%$ in asymptomatic patients (18/360). We further developed mPCR for simultaneous detection two pathogens. Sensitivity of in house mPCR was found to be $95 \%$ when evaluated against PCR for individual pathogen.

Conclusion Detection of both the pathogens in single PCR assay makes it economical both in terms of cost and time. The in house assay is highly sensitive, easy to perform and requires minimum infrastructure as well as technical expertise, making it a better option for routine diagnosis of genital infection in developing countries, which would be of great consequences in disease management.

\section{P3-S1.42 COMPLEX TREATMENT OF UROGENITAL CHLAMYDIOSIS WITH MACROLIDS AND IMIMUNOSTIMULANTS}

doi:10.1136/sextrans-2011-050108.442

T Fartushok, T Dasyuk. Danylo Halytskyy Lviv Medical University, Lviv, Ukraine

Objectives The data concerning treatment of such sexually transmitted infection as Chlamydia trachomatis (CTR) among Ukrainian population are still limited and controversial. This information is of great scientific and health care interest. The aim of investigation is to find out efficiency of urogenital chlamydiosis treatment involving new effective ways of treatment and choose the most appropriate and expedient method of treatment, which would completely meet recommendations of $\mathrm{WHO}$.

Methods We have analysed literature, records and recommendations concerning treatment of patients with chlamydial infection and concluded that there is no a perfect method of treatment, which would ensure complete clinical and laboratory cure. According to literature data, macrolids are good drugs with insignificant resistance to agent, nevertheless, recovery of a patient is, sometimes, incomplete due to complications. We have examined patients with urogenital chlamydiosis. All patients $(n=134)$ were divided into four groups and treated with antimicrobial drugs jozamicyn and azytromicyn, and immunomodulators - manax and kagotsel. Patients from the 1st group $(n=35)$ were treated with jozamicyn and manax, 2nd group ( $\mathrm{n}=35$ ) with azytromicyn and manax, 3rd group ( $n=34)$ with jozamicyn and kagotsel, 4th group $(n=30)$ with azytromicyn and kagotsel.

Results Following treatment results of our investigation showed complete laboratory and clinical recovery in $93.2 \%$ of patients from the 1 st group, $98.1 \%$ of patients from the 2 nd group, $91.8 \%$ of patients from the 3 rd group, and $93.5 \%$ of patients from the 4 th group.

Conclusion According to obtained data, our method of treatment, which was used for treatment of patients from the 2 nd group, is the most appropriate for common application in the treatment of urogenital chlamydiosis

\section{P3-S1.43 WOMEN FRIENDLY GONORRHOEA CULTURE BY SELF TAKEN VAGINAL SWABS FOR THE PURPOSE OF SURVEILLANCE OF GONORRHOEA RESISTANCE}

doi:10.1136/sextrans-2011-050108.443

${ }^{1} \mathrm{H}$ M Götz, ${ }^{2} \mathrm{~A}$ Luijendijk, ${ }^{1} \mathrm{~B}$ Nuradini, ${ }^{2} \mathrm{M}$ van Westreenen. ${ }^{1}$ Rotterdam Rijnmond Public Health Service, Rotterdam, Netherlands; ${ }^{2}$ Erasmus University Medical Centre, Rotterdam, Netherlands

Background Surveillance of Gonorrhoea resistance is a public health priority. At the Rotterdam STI clinic diagnostic tests for gonorrhoea are done by NAAT techniques from urine in men, and (self taken) vaginal swabs in women. For the purpose of resistance monitoring confirmation by culture is performed from urethra in men and cervix in women. In this study we evaluated whether culture is possible from vaginal swab, and whether women could perform this by self taken vaginal swabs.

Methods Gonorrhoea diagnostic is performed by SDA technique (BD-USA). For Culture swabs are put on GC-lect agar plates and incubated overnight at $30^{\circ} \mathrm{C}$ in $\mathrm{CO}_{2}$ atmosphere. The next day transport to the laboratory is done in $\mathrm{CO}_{2}$ jars. Cultures are examined for a maximum of $72 \mathrm{~h}$. (Presumed) Positive cultures are identified by AccuProbe (BioMerieux-France). In phase 1 culture in female patients was performed by a health care provider by cervical swabs, in phase 2 by cervical and vaginal swab, in phase 3 a vaginal swab by the patient was added.

Results In Phase 1, 8/26 (31\%) cervical cultures showed growth of gonorrhoea, 18 were negative. Mean time between PCR and culture was 18 days in positive and negative cases. In Phase 2, 21 women were cultured cervically and vaginally; 6/21 (29\%) showed growth of gonorrhoea without discrepancies between the sites. In 17 women only vaginal swabs were taken, of whom $29 \%$ positive in culture. Mean time between PCR and culture was 20 days in positive and negative cases. In phase 3 , seven women were cultured three times. $2 / 7$ cultures $(29 \%)$ were positive cervically and vaginally (professional and patient swab). The five other cases were all negative.

Conclusions Confirmation of vaginal gonorrhoea infection by culture was only achieved in 30\% despite optimal laboratory methods. Gonococci can be grown from vaginal swabs, and no discrepancy was found between health care provider and patient taken swabs. Cultures taken for surveillance of resistance can be taken by women themselves without having to undergo physical examination. 